\title{
The Effects of Hydrocortisone on Cognitive and Neural Function: A Behavioral and Event-Related Potential Investigation
}

\author{
Christopher S. Monk, Ph.D., and Charles A. Nelson, Ph.D.
}

Research indicates that glucocorticoids affect hippocampal function and the form of cognition that the hippocampus is thought to subserve, explicit memory. However, some studies suggest that glucocorticoids affect the frontal lobe, attention and working memory. Thus, it is not clear whether glucocorticoids specifically target the hippocampus and explicit memory or if the effects are more ubiquitous. By simultaneously measuring event-related potentials and behavioral performance in tasks designed to tap particular cognitive and neural processes, the present study examined the effects of hydrocortisone on 24 healthy humans. In an intentional face recognition memory task where the stimuli were presented again after a brief delay (6-18 s) and a long delay (30 min), hydrocortisone altered the $P 600$ component (an electrophysiological index of recognition memory and hippocampal activity) following the brief delay and impaired behavioral performance after the long delay. ERPS and behavioral performance were not affected in the attention and working memory tasks. These findings are consistent with reports indicating that glucocorticoids affect explicit memory and hippocampal function.

[Neuropsychopharmacology 26:505-519, 2002] (C) 2002 American College of Neuropsychopharmacology. Published by Elsevier Science Inc.
KEY WORDS: Cortisol; Hydrocortisone; Memory; Cognition; Evoked potentials

Findings from multiple levels of investigation indicate that glucocorticoids alter hippocampal function. Molecular studies in rodents demonstrate that the hippocampus has a disproportionately large number of glucocorticoid receptors and retains glucocorticoids to a greater extent

From the Institute of Child Development, Minneapolis, Minnesota (CSM, CAN), Center for Cognitive Sciences, Minneapolis, Minnesota (CSM, CAN), and Department of Pediatrics (CAN), University of Minnesota, Minneapolis, Minnesota.

Address correspondence to: Christopher S. Monk, Ph.D., 15K North Drive, Section on Development and Affective Neuroscience, Mood and Anxiety Disorders Program, National Institute of Mental Health, Bethesda, MD 20892-2670, Tel.: (301) 594-1377, Fax: (301) 402-2010, E-mail: christopher.monk@nih.gov

Received March 19, 2001; revised July 31, 2001; accepted August 23, 2001.

Online publication: 9/26/01 at www.acnp.org/citations/Npp 092601179.
(McEwen et al. 1968; McEwen et al. 1969; Aronsson et al. 1988; Sousa et al. 1989). Similarly, analysis of human hippocampal tissue from epilepsy and post-mortem samples also indicate that this structure contains high levels of glucocorticoid receptors (Seckl et al. 1991; Watzka et al. 2000a,b). At the neuronal level, chronically high levels of glucocorticoids damage hippocampal cells (Sapolsky et al. 1985, 1990; Woolley et al. 1990) and hippocampal neurons evidence reduced plasticity in the presence of this hormone (Foy et al. 1987; Shors et al. 1990; Shors and Thompson 1992). Imaging studies with humans, who hypersecrete cortisol, present reduced hippocampal volume, but no other neural alterations are apparent (Starkman et al. 1992; Lupien et al. 1998). In addition, following treatment to alleviate the hypersecretion, hippocampal volume increased by $10 \%$ and the increase in size was associated with the decrease in urinary free cortisol (Starkman et al. 1999). Moreover, acute exposure to glucocorticoids decreases activity in the hippocampus, while no changes were detected in other structures (de Leon et al. 1997). 
Meanwhile, many behavioral studies link the hippocampus to explicit memory (Zola-Morgan et al. 1986; Alvarez et al. 1995; Stern et al. 1996; Zola et al. 2000) and glucocorticoids influence this cognitive process (Starkman et al. 1992; Newcomer et al. 1994; Lupien et al. 1998; Newcomer et al. 1999). Explicit memory involves the intentional recollection of past experience and can be assessed with recognition or recall tests (Schacter 1994). Objects and faces are typical stimuli for evaluating explicit memory and hippocampal function. Indeed, some argue that the hippocampus may be more responsive to nonverbal stimuli, because they are often more perceptually complex (Stern et al. 1996). In particular, positron emisson tomography (PET) revealed hippocampal activation in an object recognition task (Schacter et al. 1995) and the right hippocampus was activated during the encoding of novel faces (Grady et al. 1995; Haxby et al. 1996). In an investigation using intracranial event-related potential (ERP) recordings, the hippocampus was activated during an object recognition memory task (Guillem et al. 1998). Consistent with these findings, healthy participants who received a high dose (160 mg a day for 4 days) of cortisol were impaired in immediate and delayed explicit memory (Newcomer et al. 1999). Similarly, $10 \mathrm{mg}$ of cortisol impaired performance in an explicit memory task as well as a mental rotation task (Kirschbaum et al. 1996). Taken together, these studies indicate that the hippocampus is involved in explicit memory, that both objects and faces are effective stimuli for activating this structure, and that cortisol affects explicit memory function.

However, glucocorticoids may not only affect the hippocampus and explicit memory. Glucocorticoid receptors reside in the frontal cortex (Meaney 1985; Diorio et al. 1993; Watzka et al. 2000b). Indeed, one study with rhesus monkeys found glucocorticoid receptors were present in high levels in structures such as the cerebellum and the hypothalamus, but were only weakly detected in the hippocampus (Sanchez et al. 2000). Moreover, glucocorticoids may affect other cognitive functions, including working memory, attention and inhibitory control. In particular, a high dose of hydrocortisone led to impairments in a working memory task (Lupien et al. 1999) and other studies revealed that patients who suffered prolonged exposure to high levels of cortisol show attentional impairments in addition to a mnemonic disruption (Mauri et al. 1993; Lupien et al. 1994). Finally, glucocorticoids may also influence emotion. Prednisone was administered to healthy males for four consecutive days and self-reported negative emotion increased on the fourth day only (Schmidt et al. 1999).

Event-related potentials (ERPs) offer a noninvasive approach for monitoring overall neural functioning. Several ERP components are linked to various cognitive functions and neural structures. The P3b, a type of P300 that is a positive waveform occurring approximately $300 \mathrm{~ms}$ following stimulus onset, is associated with working memory as well as attention (Squires et al. 1975; Donchin and Coles 1988; Ruchkin et al. 1990) and is generated by multiple structures including the parietal, temporal and frontal cortices (reviewed in McCarthy and Wood 1987; Knight et al. 1998). The P600 (also referred to as the late positive component, the repetition effect, and the memory evoked shift) occurs between 500-800 ms following stimulus presentation and is linked to recognition memory (Paller et al. 1988, 1999; Smith 1993). Moreover, this component may be partially generated by the hippocampus. Using intracranial ERP recordings in the hippocampus, patients with Ammon's horn sclerosis evidenced reduced amplitude in the positive waveform measured between 300 and 700 ms following stimulus presentation in a recognition memory task (Grunwald et al. 1999). Similarly, in an explicit memory task with indwelling electrodes, the hippocampus elicited more activity for remembered items than non-remembered items between 600 and $2000 \mathrm{~ms}$ following stimulus onset (Fernández et al. 1999). In another investigation using intracranial ERP recordings, the authors describe detection of a P600 in the hippocampus in an object recognition memory task (Guillem et al. 1998). Recently, Düzel and colleagues (2001) recorded scalp ERPs from an individual who sustained isolated bilateral hippocampal and parahippocampal damage early in life and documented an absence of the P600 in response to previously seen words. Finally, the N400 is a negative component generated 400 ms following stimulus onset; it is greater for novel stimuli (Swick and Knight 1995, 1997) and there is some evidence to suggest that it is linked to hippocampal activation (Guillem et al. 1998).

In the present investigation, participants received hydrocortisone in one visit and a placebo in another. Explicit memory, working memory and attention tasks were given while behavioral performance and ERPs were measured. The explicit memory task involved two components: (1) in the short-term memory (STM) task, the stimuli were initially presented and displayed again following a 6-18 s delay; (2) for the long-term memory (LTM) task, stimuli from the STM task were presented again along with novel stimuli after a 30 min delay. In both tasks, participants determined which stimuli were new and which were repeats. Since the delay duration of the STM task was within the capacity of working memory (Smith and Jonides 1998), performance did not necessarily measure explicit memory. However, the STM task can be considered the encoding phase for explicit memory and the LTM task is the test of explicit memory. There were separate STM and LTM explicit memory tasks with faces and objects. For the working memory task, a "2-back" task was used. As in explicit memory, faces were presented in one compo- 
nent and objects in another. In the attention task, a letter or number was presented for a very short duration and subjects were asked to press one button for the target stimulus and another button for nontarget stimuli. In addition, blood pressure, pulse and mood were monitored.

It was predicted that hydrocortisone would disrupt explicit memory performance as measured behaviorally in the LTM task. Furthermore, hydrocortisone would alter the P600 ERP component at STM task as well as the LTM task, and hydrocortisone would influence the N400 component at STM. Moreover, we also predicted that the P600 would be greater for previously seen stimuli in the STM as well as the LTM tasks; the N400 would be greater for the novel stimuli in the STM tasks; and target stimuli in the working memory and attention tasks would yield greater P3b components. Finally, correlational analysis was conducted between the behavioral and physiological measures that were affected by hydrocortisone. In particular, following work demonstrating that the P600 during incidental encoding predicted later memory (Paller et al. 1987, 1988), it was predicted that the P600 amplitude would be related to explicit LTM performance.

\section{METHODS}

\section{Participants}

Twenty-six healthy, right-handed adult subjects between the ages of 18 and 34 years participated in this study. The data from one participant were excluded from analysis due to a bad mastoid electrode and another participant was excluded because of an injury between visits that necessitated the use of pain medication, leaving 24 subjects (12 women). Subjects were excluded from participation for any of the following reasons: use of glucocorticoids (last 3 years), hormonal birth control, or psychotropic medication; current or past diagnosis of any psychological disorder (including depression, anorexia or bulimia); head injury involving loss of consciousness for five or more minutes; pregnancy; weight that was $15 \%$ more or less than the ideal body weight for height; use of tobacco; abnormal sleep pattern (defined as less than $6.5 \mathrm{~h}$ of sleep a night and/or falling asleep after 2:00 A.M. and/or waking up after 11:00 A.M.); consumption of more than 10 alcoholic drinks in an average week; and exercise regimen in excess of $10 \mathrm{~h}$ per week. Furthermore, subjects were asked to schedule their participation at a time remote from major stressors (i.e., exams, rigorous exercise, or recent air travel across more than one time zone), to avoid alcohol on the day of the appointment, and to refrain from eating or exercising two hours before the study was to begin. In addition, female subjects were asked to schedule their participation in the first two weeks of their menstrual cycle. Finally, in order to control for circadian rhythms, testing of all subjects began at 2:00 P.M. and ended at 5:00 P.M., a period of relatively low cortisol levels.

\section{Tasks}

Explicit Memory. There were two recognition memory tasks (one with faces and the other with objects) and each was comprised of two phases. During the first phase, subjects saw a sequence of images on the computer screen. The stimuli were presented for $500 \mathrm{~ms}$ and the duration between stimulus presentations varied randomly between 2100 and $2600 \mathrm{~ms}$ for this and the other memory tasks. There were 60 trials in the faces task and 90 trials in the objects task. Within these trials, 30 novel stimuli were presented along with 30 repeats (i.e., each of the 30 stimuli were presented twice across the 60 trials) and, in the objects task only, there were 30 similar distractors (described below). The repeated stimuli were presented 6 to $18 \mathrm{~s}(2-6$ trials) after the first presentation of that particular stimulus. Subjects were given a button box and instructed to press the left button with their right thumb for novel stimuli, and to press the right button with their right thumb for repeat stimuli. The experimenter did not indicate to the subject when the second presentation of the stimulus might occur, nor was the subject informed about how many trials there would be. Therefore, by necessity in a continuous performance task with the specified minimum and maximum delay for repetition, the first two trials must contain novel stimuli and the last two trials must have repeat stimuli. However, while the subjects knew that the first trial must contain a novel stimulus, they were not aware that the second trial would be novel. Further, since they did not know the number of trials in the tasks, they could not anticipate when the last trial would occur, which must have a repeat stimulus. In addition, subjects were told that these stimuli would be presented again after a half hour delay and they would be asked to identify the stimuli as novel or repeats following the long delay.

After the initial phase, there was a 30-min delay. During this period, the working memory task and the attention task were administered (described below). Following the delay, the explicit memory task was given. In the faces task, there were 60 trials and 30 contained the 30 stimuli that they saw $30 \mathrm{~min}$ before and the other 30 trials contained 30 novel stimuli. For objects, there were 90 trials; 30 contained the same stimuli that subjects saw $30 \mathrm{~min}$ before, 30 were novel and 30 were similar distractors (described below). Subjects were instructed to press the left button with their right thumb to indicate a novel stimulus and press the right button with their right thumb to identify the stimulus as a repeat. 
Working Memory. The working memory task was modeled after the fMRI work of Cohen et al. (Cohen et al. 1994), but different types of stimuli were used. Separate tasks for faces and objects were provided and each task was divided into two phases of 3-min blocks. Six stimuli were repeatedly presented across 60 trials per phase. Subjects pressed the right button with their right thumb when they believed that the stimulus matched the one they saw two trials before and pressed the left button with their right thumb when it did not. Six seconds elapsed between two trials and so participants were only required to maintain a memory for the previous $6 \mathrm{~s}$, but this information had to be continuously updated. The working memory task with faces and the task with objects each contained 30 trials where the stimulus was the same stimulus that was presented 2 trials before. These were the target trials. The remaining 90 trials in each block were nontarget distractors.

Attention. In the attention task, letters and numbers were sequentially presented for $35 \mathrm{~ms}$ and this was immediately followed by a mask (" $X$ "), which was presented for $857 \mathrm{~ms}$. One stimulus was the target and subjects were to press the right button with their right thumb whenever it appeared. When any of the other stimuli were presented, subjects were to press the left button with their right thumb. The inter-stimulus interval varied randomly between $1065 \mathrm{~ms}$ and $1565 \mathrm{~ms}$ for this task. Participants were given this task twice during each visit at different points of the cognitive testing. Each phase contained 120 trials, 30 of which contained the target stimulus; the other 90 contained nontarget distractors (45 similar distractors; 45 dissimilar distractors).

Stimuli. For all memory tasks, the stimuli were images of everyday objects (e.g., a phone) and women's faces presented on a computer screen. All stimuli were of equal size $(6.5 \mathrm{~cm} \times 6.5 \mathrm{~cm})$ and subtended a visual angle of $4.65^{\circ} \times 4.65^{\circ}$. In addition, each picture of the objects had two similar pictures, which acted as distractors. Thus, in the test of short-term memory, a picture was presented (e.g., a push button phone) and the subject was to identify it as a new picture. This picture was then presented again within the next 6-18 $\mathrm{s}$ and the subject was to identify it as a repeat. However, either before or after the second presentation of the same stimulus (half were before and half were after), a similar picture was presented (e.g., a cordless phone) and the subject was instructed to identify this image as new. Similarly, in the test of long-term memory, the original stimulus (e.g., push button phone) was presented again following a half hour delay and the participant was to identify it as a repeat. Again, either before or after the repeat was presented, another similar stimulus was presented (e.g., a cellular phone) and the subject was to identify this as new.

Face and object stimuli were counterbalanced across drug condition and gender, and they were used equally often as the repeated stimuli and the distractors. In addition, a different set of 6 faces and 6 objects $(2$ sets of 3 similar objects) for each subject were drawn from a pool of available stimuli for the working memory tasks with faces and objects.

The attention task utilized the characters $b, d, p, q, A$, 1 , and 7 . The stimuli were approximately $3 \mathrm{~cm} \times 3 \mathrm{~cm}$ and subtended a visual angle of $2.15^{\circ} \times 2.15^{\circ}$. The target stimulus was $b, d, p$ or $q$ for each subject (the target stimulus was counterbalanced across subjects, drug order and gender) and the other three served as the similar distractors, while the A, 1, and 7 were the dissimilar distractors.

\section{Procedure}

Participants arrived at 2:00 P.M. and were asked to sit and relax for half an hour to ensure that their walk to the lab did not alter the physiological measures. During this half hour delay, all procedures were described and a consent form was then provided for signing. After the half-hour rest period, subjects then provided a saliva sample to give a baseline measure of cortisol. In addition, pulse and blood pressure were measured. Finally, the Positive and Negative Affective Schedule (PANAS; Watson et al. 1988) was also given four times during the procedure. This questionnaire asked subjects to rate themselves on feelings of anxiety, depression and alertness. These measures of cortisol, pulse, blood pressure and mood were taken three times during the procedure: baseline, once in the middle of the cognitive tasks and then at the completion of the tasks. In addition, the PANAS was administered an additional time at baseline. The first time, subjects were asked to rate how they felt in general. Then, subjects were asked to rate how they felt at the moment. In the two other administrations of the PANAS, subjects were asked about their mood at the moment.

Following the administration of the baseline measures (salivary cortisol, pulse, blood pressure and PANAS), a nurse administered $30 \mathrm{mg}$ of hydrocortisone orally during one visit and a placebo during the other visit (the two visits were separated by at least two days). This level of hydrocortisone was chosen, as it was thought to approximate a peak physiological response. Half the women and half the men received the hydrocortisone in the first visit and the other half received the hydrocortisone in the second visit. Investigational Pharmacy at the University of Minnesota determined the randomization for the drug schedule. For the first six subjects, Investigational Pharmacy provided the experimenter with two bottles of capsules. One bottle was labeled "red" and the other labeled "blue." Investigational pharmacy instructed the experimenter which bottle to provide to each subject on visit 1 and 2 . For the remaining 18 subjects, Investigational Phar- 
macy provided two bottles of pills for each subject. One bottle was labeled "visit 1" and the other was labeled "visit 2." The experimenter, the nurse and the participant were blind to the drug treatment. Following this, subjects waited $45 \mathrm{~min}$ in order to allow the drug to take effect. After the tasks and other measures were completed, subjects filled out a questionnaire to determine if they felt they were exposed to hydrocortisone.

Between the short-term memory task and the explicit memory task for the faces and objects, respectively, there was a 30-min delay. During this period, the working memory task for the other type of stimulus was given (e.g., if the subject had faces for the explicit memory task, s/he was given objects for the working memory task) and the attention task was provided. Half the female and male subjects received the explicit memory task for faces first with the working memory task for objects during the delay and the other half received the explicit memory task for objects first with the working memory task for faces during the delay. In addition, half the female and male subjects received the attention task before the working memory task and the other half received the working memory task before the attention task. (All these variables were also counterbalanced across order of drug exposure.)

\section{Equipment}

EEG data were acquired with a Grass Neurodata Acquisition System ${ }^{\circledR}$ with Model 12A5 amplifiers. The computer used for data acquisition was a Dell Optiplex ${ }^{\circledR}$ GX1 with a Dell Ultrascan ${ }^{\circledR} 1000$ HS series monitor (refresh rate was $85 \mathrm{~Hz}$ ). The button box was manufactured at the University of Minnesota. The dimensions of the box were $9 \times 5.5 \times 2 \mathrm{~cm}$. The diameter of each button was $0.8 \mathrm{~cm}$ and the distance between the two buttons was $2.5 \mathrm{~cm}$.

Cortisol Measure and Analysis. The following procedure was used to obtain the salivary cortisol measures. Participants chewed a piece of Trident ${ }^{\circledR}$ Original flavor gum, and then gently blew their saliva through a short straw into a cryovial. Saliva samples were then stored at $-20^{\circ} \mathrm{C}$ until they were assayed for cortisol levels at the Endocrine Lab at Fairview University Medical Center. Samples were assayed using the CIBA Magic Cortisol Assay RIA kit, utilizing antibody covalently bound to magnetic particles (Kirschbaum et al. 1989). Interand intra-assay coefficients of variation were less than $13 \%$. Each sample was assayed in duplicate in the same assay batch. The Pearson $r$ correlation between duplicates was 0.997 within the cortisol condition and 0.992 for the placebo condition.

A mean of the two assays for each sample was derived and a repeated measures univariate analysis of variance (ANOVA) was carried out to examine salivary cortisol across drug condition (hydrocortisone and pla- cebo) and time (baseline, middle and end). Multiple comparisons with Bonferroni corrections were then used to locate specific effects.

Analysis of Subjects' Belief That They Were Given Hydrocortisone. At the completion of each visit, subjects were asked whether they thought they took hydrocortisone. Since subjects' responses to this question in their second visit could be influenced by their response in the first visit (i.e., the responses were not independent), only responses in their first visit were analyzed. A chi-square was used to determine whether subjects were aware of when they took the hydrocortisone.

Behavioral Measures and Analyses. Button press accuracy and reaction time were the behavioral measures for all tasks. Paired $t$-tests and ANOVAs were conducted to examine the effects of hydrocortisone for each task and measure.

ERP Measures and Analyses. EEG activity was recorded from 28 tin electrodes that were embedded in an elastic cap. Placement of the electrodes was based on an adaptation of the international 10-20 system (Jasper 1958) with 9 additional electrodes added to provide fuller coverage. Specifically, electrodes were recorded from, Fz, Pz, Cz, POz, F3/4, F7/8, AF3/4, FC5/6, FC1/ 2, C4/3, T3/4, T5/6, CP5/6, P3/4, PO3/4, and O1/2. In addition, data were acquired from each mastoid (A1/2) and eye activity was monitored with electrodes placed vertically above and below one eye. All scalp electrodes were referenced to $\mathrm{Cz}$ and then algebraically re-referenced to an average mastoid.

The EEG was amplified (50 k) and filtered (halfamplitude bandpass $0.1-30 \mathrm{~Hz}$ and $60 \mathrm{~Hz}$ notch filter) for all electrodes. The EEG was continuously digitized at $200 \mathrm{~Hz}$ and electromyographic artifact that exceeded $100 \mu \mathrm{V}$ was rejected before averaging. Due to an inadvertent programming error, the working memory with objects task was sampled at $250 \mathrm{~Hz}$. This was done with all subjects in all conditions. No analyses were carried out to compare this task with any other task. Therefore, no comparisons were made across different sampling rates.

Mean amplitudes were referred to a $100 \mathrm{~ms}$ prestimulus baseline period. For the analyses electrodes were grouped by their position on the scalp. The groups were as follows: Fz, F3, F4, F7, F8, AF3 and AF4 comprised the frontal group; $\mathrm{Cz}, \mathrm{FC} 1, \mathrm{FC} 2, \mathrm{FC} 5, \mathrm{FC} 6, \mathrm{C} 3$ and $\mathrm{C} 4$ were the central group; Pz, P3, P4, CP5, CP6 represented the parietal group; and $\mathrm{POz}, \mathrm{PO} 3, \mathrm{PO} 4, \mathrm{O} 1$ and $\mathrm{O} 2$ were the occipital group. As is standard with ERP studies (e.g., Smith 1993; Nielsen-Bohlman and Knight 1995; Düzel et al. 1997; Schnyer et al. 1997) only trials with correct button presses were included in the analysis. The following windows were used for analysis to capture the ERP components of interest for each task. In the short-term and long-term memory tasks, the windows were $350-450 \mathrm{~ms}$ (N400) and $600-1000 \mathrm{~ms}$ 
(P600). The window for the working memory tasks was 250-600 ms (P3b). For the attention task, the window was 200-700 (P3b). Separate repeated measures univariate ANOVAs with Greenhouse-Geisser corrections (when necessary) were carried out on mean amplitudes within the entire window for drug (placebo or hydrocortisone), stimulus condition (new or repeated for the short-term and long-term memory tasks and target or nontarget for the working memory and attention tasks), and electrode. All multiple comparison tests used Bonferroni corrections and the simple effects tests used a pooled error term from the interaction and the main effect of interest.

Blood Pressure, Pulse Measure and Their Analyses. Blood pressure and pulse were monitored with a sphygmomanometer (Colin Press-Mate; Medical Instruments Corp; Model BP-8800C). A univariate repeated measures ANOVA was conducted with the factors of drug and time to determine whether there were any effects of hydrocortisone on these measures.

Analysis of the Relation between the Physiological and Behavioral Measures. In order to examine the relation between ERPs and behavior, correlational analyses were conducted. Pearson $r$ correlational analyses were used with the P600 component at STM and behavioral performance at LTM within the two drug conditions.

\section{RESULTS}

Additional figures and the tables with the values from the analyses appear in the online version of this article at www.acnp.org/citations/Npp100101178.

\section{Salivary Cortisol}

Hydrocortisone increased salivary cortisol levels (Figure 1). An ANOVA revealed a main effect of drug, $F_{1,23}=$ 74.278, $p<.001$ and follow-up tests with Bonferroni

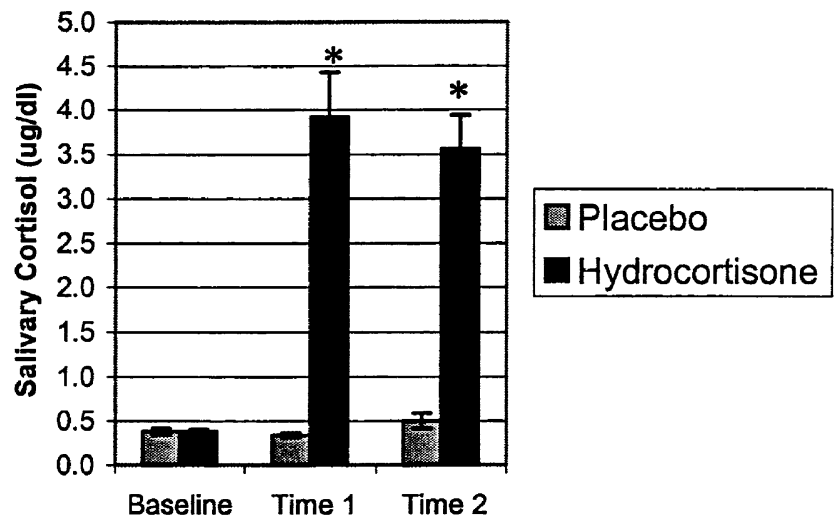

Figure 1. Salivary cortisol measure. Error bars represent standard error. corrections showed that there was not a significant difference at baseline, $p=.981$, but significant differences were found at Time $1, p<.001$ and Time $2, p<.001$.

Subjects' Belief That They Were Given Hydrocortisone. A chi-square was conducted on the subjects' response to whether they took the drug. Subjects were not able to determine whether they received the hydrocortisone vs. the placebo, $\chi^{2}(2)=2.250, p=.325$.

Behavioral Data. Results for behavioral accuracy are presented in Table 1. Hydrocortisone led to a decrease in performance in the face recognition memory task following the long delay, but not the short delay. Meanwhile, there were no alterations from hydrocortisone in recognition memory for objects following the short and long delays, and no effects were detected in working memory or attention. The reaction time data are presented in Table 2. While stimulus affected reaction time in some of the tasks, there were no effects of drug and there was no drug and stimulus interaction.

\section{Electrophysiological Data}

Short-term Face Recognition N400. The N400 is typically manifested over the central and sometimes the frontal leads. Therefore, analyses were confined to those regions. There was a significant effect of stimulus on the N400 (novel stimuli were associated with greater negative deflections) over the central leads, but there was no effect of drug and there was no drug and stimulus interaction.

Short-term Face Recognition P600. As shown in Table 3, there was an interaction of drug and stimulus on the P600. Specifically, as is illustrated in midline lead waveforms (Figure 2), difference waveforms (Figure 3) and interaction graphs (Figure 4), hydrocortisone increased the response to novel stimuli on the frontal leads. In the more posterior leads, hydrocortisone was associated with a decrease in the response to repeat stimuli

Long-term Face Recognition P600. While this task elicited a P600 that was maximal at approximately 700

Table 1. Behavioral Performance Represented in Percent

\begin{tabular}{lllllllllr}
\hline & \multicolumn{2}{c}{ Mean } & & \multicolumn{2}{c}{ SD } & & & \\
\cline { 2 - 3 } Task & Plac & Cort & & Plac & Cort & df & $\boldsymbol{t}$ & \multicolumn{1}{c}{$\boldsymbol{p}$} \\
\hline STM face & 78.64 & 79.05 & & 9.71 & 8.00 & 23 & 0.25 & .81 \\
LTM face & 71.36 & 66.09 & & 8.69 & 9.69 & 23 & 2.62 & $<.02$ \\
STM object & 89.77 & 90.09 & & 5.48 & 5.59 & 23 & 0.37 & .72 \\
LTM Object & 85.23 & 85.28 & & 5.63 & 8.12 & 23 & 0.04 & .97 \\
WM Face & 84.33 & 84.69 & & 7.91 & 10.14 & 23 & 0.22 & .83 \\
WM Object & 86.77 & 86.22 & 6.78 & 8.85 & 23 & 0.44 & .66 \\
Attention 1 & 77.40 & 76.22 & & 19.98 & 22.32 & 23 & 0.65 & .53 \\
Attention 2 & 80.10 & 80.14 & & 18.49 & 20.16 & 23 & 0.02 & .99 \\
\hline
\end{tabular}

STM $=$ short-term memory (6-18 $\mathrm{s}$ delay); LTM $=$ long-term memory (30 $\mathrm{min}$ delay); $\mathrm{WM}=$ working memory; plac $=$ placebo ; cort $=$ hydrocortisone. 
Table 2. Reaction Time Response in Milliseconds. Dis Novel and Sim Novel Denote Dissimilar Novel Stimuli and Similar Novel Stimuli in the STM and LTM Objects Memory Tasks. Sim Dis and Dissim Dis Indicates Similar Distractor and Dissimilar Distractor in the Attention Tasks

\begin{tabular}{|c|c|c|c|c|c|c|c|}
\hline \multicolumn{4}{|c|}{ REACTION TIME (SD) } & EFFECT & df & $\mathbf{F}$ & $p$ \\
\hline \multicolumn{8}{|c|}{ STM Face } \\
\hline & Novel & Repeat & & Drug & 1,23 & 0.270 & 0.608 \\
\hline$\underline{\text { Plac }}$ & $\begin{array}{l}1084 \\
(146)\end{array}$ & $\begin{array}{l}1093 \\
(149)\end{array}$ & & Stim & 1,23 & 0.008 & 0.931 \\
\hline Cort & $\begin{array}{l}1110 \\
(149)\end{array}$ & $\begin{array}{l}1097 \\
(132)\end{array}$ & & Stim $\times$ Drug & 1,23 & 0.886 & 0.356 \\
\hline \multicolumn{8}{|c|}{ LTM Face } \\
\hline \multirow[b]{2}{*}{$\underline{\text { Plac }}$} & $\underline{\text { Novel }}$ & $\underline{\text { Repeat }}$ & & Drug & 1,23 & 0.331 & 0.571 \\
\hline & $\begin{array}{l}1153 \\
(124)\end{array}$ & $\begin{array}{l}1107 \\
(100)\end{array}$ & & Stim & 1,23 & 5.604 & $<0.05$ \\
\hline Cort & $\begin{array}{l}1139 \\
(156)\end{array}$ & $\begin{array}{l}1093 \\
(132)\end{array}$ & & Stim $\times$ Drug & 1,23 & 0.000 & 1.000 \\
\hline \multicolumn{8}{|c|}{ STM Objects } \\
\hline & Dis Novel & $\underline{\text { Sim Novel }}$ & $\underline{\text { Repeat }}$ & Drug & 1,23 & 1.181 & 0.288 \\
\hline$\underline{\text { Plac }}$ & $\begin{array}{c}951 \\
(173)\end{array}$ & $\begin{array}{l}1081 \\
(192)\end{array}$ & $\begin{array}{l}1089 \\
(177)\end{array}$ & Stim & 2,46 & 29.205 & $<0.001$ \\
\hline$\underline{\text { Cort }}$ & $\begin{array}{c}971 \\
(156)\end{array}$ & $\begin{array}{l}1104 \\
(162)\end{array}$ & $\begin{array}{l}1099 \\
(180)\end{array}$ & Stim $\times$ Drug & 2,46 & 0.173 & 0.842 \\
\hline \multicolumn{8}{|c|}{ LTM Objects } \\
\hline \multirow[b]{2}{*}{$\underline{\text { Plac }}$} & $\underline{\text { Dis Novel }}$ & $\underline{\text { Sim Novel }}$ & $\underline{\text { Repeat }}$ & Drug & 1,23 & 2.717 & 0.113 \\
\hline & $\begin{array}{c}951 \\
(153)\end{array}$ & $\begin{array}{l}1154 \\
(167)\end{array}$ & $\begin{array}{l}1079 \\
(161)\end{array}$ & Stim & 2,46 & 27.641 & $<0.001$ \\
\hline$\underline{\text { Cort }}$ & $\begin{array}{c}921 \\
(130)\end{array}$ & $\begin{array}{l}1119 \\
(165)\end{array}$ & $\begin{array}{l}1038 \\
(245)\end{array}$ & Stim $\times$ Drug & 2,46 & 0.300 & 0.937 \\
\hline \multicolumn{8}{|c|}{ WM Faces } \\
\hline$\underline{\text { Plac }}$ & $\begin{array}{c}985 \\
(153)\end{array}$ & $\begin{array}{l}1004 \\
(165)\end{array}$ & & Stim & 1,23 & 2.788 & 0.109 \\
\hline Cort & $\begin{array}{c}978 \\
(195)\end{array}$ & $\begin{array}{l}1020 \\
(172)\end{array}$ & & Stim $x$ Drug & 1,23 & 1.972 & 0.174 \\
\hline \multicolumn{8}{|c|}{ WM Objects } \\
\hline \multirow[b]{2}{*}{$\underline{\text { Plac }}$} & $\underline{\text { Target }}$ & Nontarget & & Drug & 1,23 & 0.157 & 0.695 \\
\hline & $\begin{array}{c}954 \\
(152)\end{array}$ & $\begin{array}{l}1006 \\
(146)\end{array}$ & & Stim & 1,23 & 8.050 & $<0.01$ \\
\hline$\underline{\text { Cort }}$ & $\begin{array}{c}942 \\
(161)\end{array}$ & $\begin{array}{r}997 \\
(169)\end{array}$ & & Stim $\times$ Drug & 1,23 & 0.044 & 0.836 \\
\hline \multicolumn{8}{|c|}{ Attention 1} \\
\hline \multirow[b]{2}{*}{$\underline{\text { Plac }}$} & $\underline{\text { Target }}$ & $\underline{\text { Sim Dist }}$ & $\underline{\text { Dissim Dis }}$ & Drug & 1,23 & 0.156 & 0.697 \\
\hline & $\begin{array}{c}651 \\
(108)\end{array}$ & $\begin{array}{c}598 \\
(91)\end{array}$ & $\begin{array}{c}575 \\
(86)\end{array}$ & Stim & 2,46 & 28.250 & $<0.005$ \\
\hline$\underline{\text { Cort }}$ & $\begin{array}{l}647 \\
(77)\end{array}$ & $\begin{array}{r}588 \\
(105)\end{array}$ & $\begin{array}{l}578 \\
(90)\end{array}$ & Stim $x$ Drug & 2,46 & 0.323 & 0.726 \\
\hline \multicolumn{8}{|c|}{ Attention 2} \\
\hline \multirow{2}{*}{$\underline{\text { Plac }}$} & $\underline{\text { Target }}$ & $\underline{\text { Sim Dist }}$ & $\underline{\text { Dissim Dis }}$ & Drug & 1,23 & 0.680 & 0.418 \\
\hline & $\begin{array}{c}636 \\
(100)\end{array}$ & $\begin{array}{c}586 \\
(84)\end{array}$ & $\begin{array}{c}553 \\
(81)\end{array}$ & Stim & 2,46 & 23.121 & $<0.005$ \\
\hline Cort & $\begin{array}{c}641 \\
(111)\end{array}$ & $\begin{array}{l}591 \\
(98)\end{array}$ & $\begin{array}{l}568 \\
(76)\end{array}$ & Stim $\times$ Drug & 2,46 & 0.293 & 0.743 \\
\hline
\end{tabular}

$\mathrm{STM}=$ short-term memory (6-18 $\mathrm{s}$ delay); LTM = long-term memory ( 30 min delay); $\mathrm{WM}=$ working memory; plac $=$ placebo; cort $=$ hydrocortisone.

ms, no significant differences were found for drug or stimulus and, unlike the P600 in the test of short-term memory, there was not a significant interaction.

Short-term Object Recognition N400. As with the faces for this component, there was no effect of drug and there was no drug and stimulus interaction for the N400, but there was an effect of stimulus over both the frontal and central leads. Moreover, using Bonferronicorrected tests on stimuli, it was revealed that the novel stimuli elicited a larger negative component than the 
Table 3. Mean ERP Amplitudes for the P600 in the Face Recognition Memory Task Following the Short Delay

\begin{tabular}{|c|c|c|c|c|c|c|c|}
\hline & & \multicolumn{2}{|c|}{ M (SD) } & df & $\mathbf{F}$ & $p$ & Simple Effects \\
\hline \multicolumn{8}{|l|}{ FRONTAL } \\
\hline \multirow[t]{3}{*}{ Drug } & & $\underline{\text { Plac }}$ & Cort & & & & \\
\hline & & $\overline{3.514}$ & $\overline{3.816}$ & 1,23 & 0.552 & 0.465 & \\
\hline & & $(2.366)$ & $(2.332)$ & & & & \\
\hline \multirow[t]{3}{*}{ Stimulus } & & $\underline{\text { Novel }}$ & $\underline{\text { Repeat }}$ & & & & \\
\hline & & $\overline{3.900}$ & $\overline{3.430}$ & 1,23 & 2.090 & 0.162 & \\
\hline & & $(1.999)$ & $(2.518)$ & & & & \\
\hline \multirow[t]{5}{*}{ Drug $\times$ Stim } & & Novel & Repeat & & & & \\
\hline & $\underline{\text { Plac }}$ & $\overline{3.474}$ & 3.555 & 1,23 & 6.233 & $<0.025$ & novel vs. repeat (plac), $p=.84$ \\
\hline & & $(2.102)$ & $(2.959)$ & & & & novel vs. repeat (cort), $p<.02$ \\
\hline & Cort & 4.326 & 3.305 & & & & cort vs. plac (novel), $p=.052$ (trend) \\
\hline & & $(2.376)$ & $(0.676)$ & & & & cort vs. plac (repeat), $p=.625$ \\
\hline \multicolumn{8}{|l|}{ CENTRAL } \\
\hline \multirow[t]{3}{*}{ Drug } & & $\underline{\text { Plac }}$ & Cort & & & & \\
\hline & & 4.825 & $\overline{5.017}$ & 1,23 & 0.123 & 0.729 & \\
\hline & & $(3.018$ & $(3.042)$ & & & & \\
\hline \multirow[t]{3}{*}{ Stimulus } & & Novel & $\underline{\text { Repeat }}$ & & & & \\
\hline & & $\overline{5.000}$ & $\overline{4.842}$ & 1,23 & 0.126 & 0.726 & \\
\hline & & (2.435) & $(3.351)$ & & & & \\
\hline \multirow[t]{5}{*}{ Drug $\times$ Stim } & & $\underline{\text { Novel }}$ & $\underline{\text { Repeat }}$ & & & & \\
\hline & $\underline{\text { Plac }}$ & $\overline{4.605}$ & $\overline{5.045}$ & 1,23 & 4.322 & $<0.05$ & novel vs. repeat (plac), $p=.515$ \\
\hline & & $(2.802)$ & $(3.958)$ & & & & novel vs. repeat (cort), $p<.04$ \\
\hline & Cort & 5.395 & 4.638 & & & & cort vs. plac (novel), $p=.205$ \\
\hline & & $(2.900)$ & $(3.390)$ & & & & cort vs. plac (repeat), $p=.524$ \\
\hline \multicolumn{8}{|l|}{ PARIETAL } \\
\hline \multirow[t]{3}{*}{ Drug } & & $\underline{\text { Plac }}$ & Cort & & & & \\
\hline & & 3.428 & 3.090 & 1,23 & 1.361 & 0.255 & \\
\hline & & $(2.636)$ & $(2.303)$ & & & & \\
\hline \multirow[t]{3}{*}{ Stimulus } & & Plac & Repeat & & & & \\
\hline & & $\overline{3.207}$ & 3.312 & 1,23 & 0.067 & 0.799 & \\
\hline & & $(2.235)$ & $(2.895)$ & & & & \\
\hline \multirow[t]{5}{*}{ Drug $\times$ Stim } & & Novel & $\underline{\text { Repeat }}$ & & & & \\
\hline & $\underline{\text { Plac }}$ & $\overline{3.263}$ & $\overline{2.917}$ & 1,23 & 4.308 & $<0.05$ & novel vs. repeat (plac), $p=.290$ \\
\hline & & $(2.244)$ & $(2.719)$ & & & & novel vs. repeat (cort), $p=.382$ \\
\hline & Cort & 3.150 & 3.707 & & & & cort vs. plac (novel), $p=.694$ \\
\hline & & $(2.376)$ & $(3.395)$ & & & & cort vs. plac (repeat), $p=.077$ \\
\hline
\end{tabular}

Note: Mean amplitudes in all tables are expressed in microvolts. Words in parentheses indicate which condition the simple effect is examining.

repeat and the similar stimuli (images that were similar to repeats, but somewhat different).

Short-term Object Recognition P600. Examination of the P600 in the short-term object recognition task showed that there was no effect of drug, nor was there a drug and stimulus interaction, but there was an effect of stimulus. Contrary to expectations, novel stimuli elicited a greater response than the repeats in the frontal leads, but posthoc analysis with the three types of stimuli were not significant. Typically, the P600 is greater to repeated stimuli and is thought to be maximal over the parietal leads.

Long-term Object Recognition P600. As with the test of short-term memory with objects, there was no effect of drug and there was no drug and stimulus interaction in the P600. However, the effect of stimulus was significant. In particular, repeat and similar stimuli elicited significantly larger P600s than the novel stimuli over frontal, central and parietal leads.
Working Memory for Faces. The working memory for faces task elicited a P3b component that was maximal over the parietal leads and was greater to target than nontarget stimuli. There was no effect of drug, nor was there a drug and stimulus interaction; only the effect of stimulus (target and nontarget) was significant. In particular, the presentation of target stimuli (stimuli that were the same as ones presented two trials before) evoked larger $\mathrm{P} 3 \mathrm{~b}$ responses.

Working Memory for Objects. A similar pattern of results was found for working memory for objects as for faces. No significant effects were found from drug and there was no interaction between drug and stimulus, but the stimulus did modulate the ERP response in the central and parietal leads. Specifically, trials with target stimuli led to larger P3b components. However, unlike the working memory for faces task, no differences due to stimulus were found in the frontal leads. 

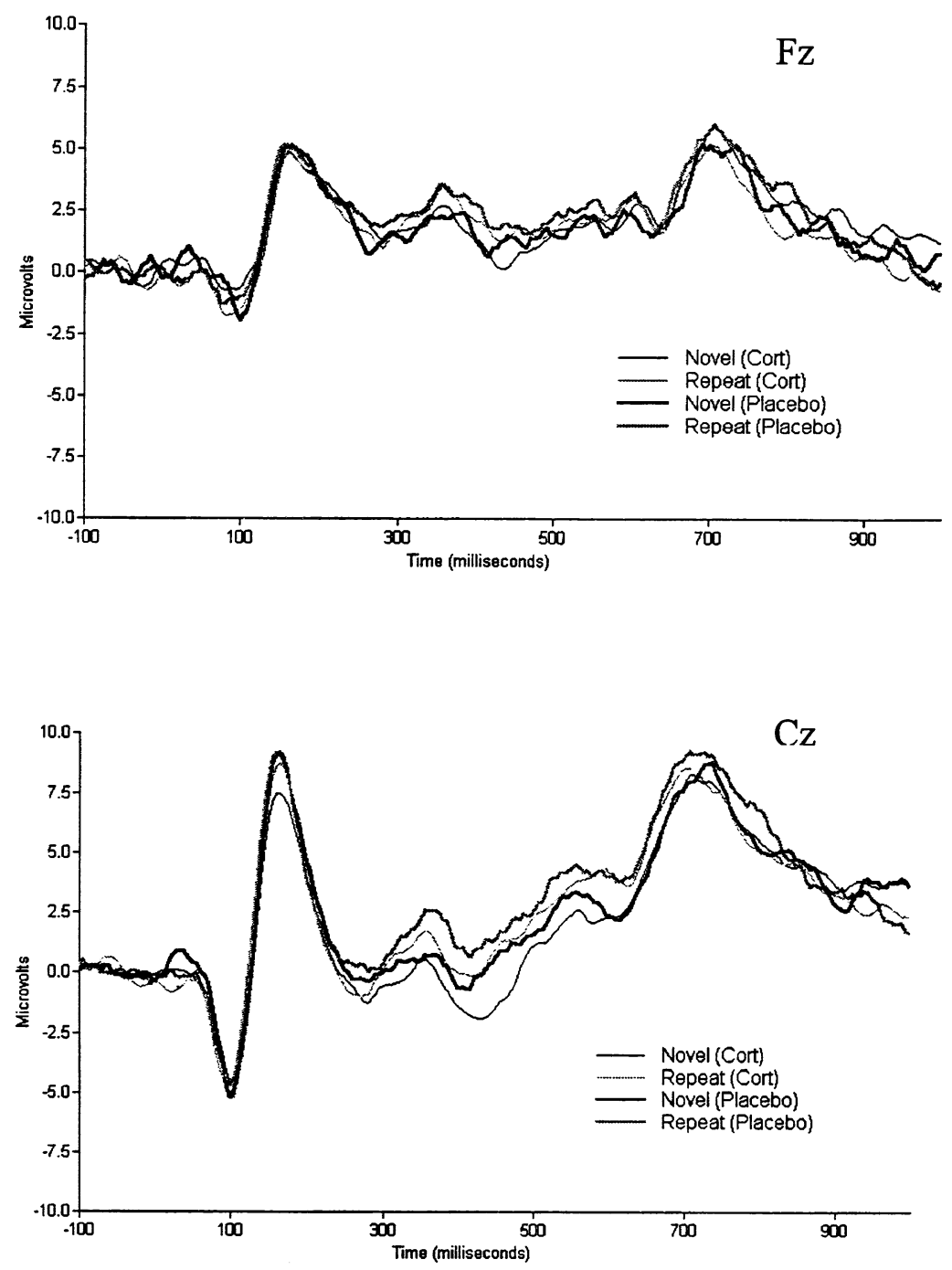

Figure 2. ERP results for the short-term recognition memory task with faces.

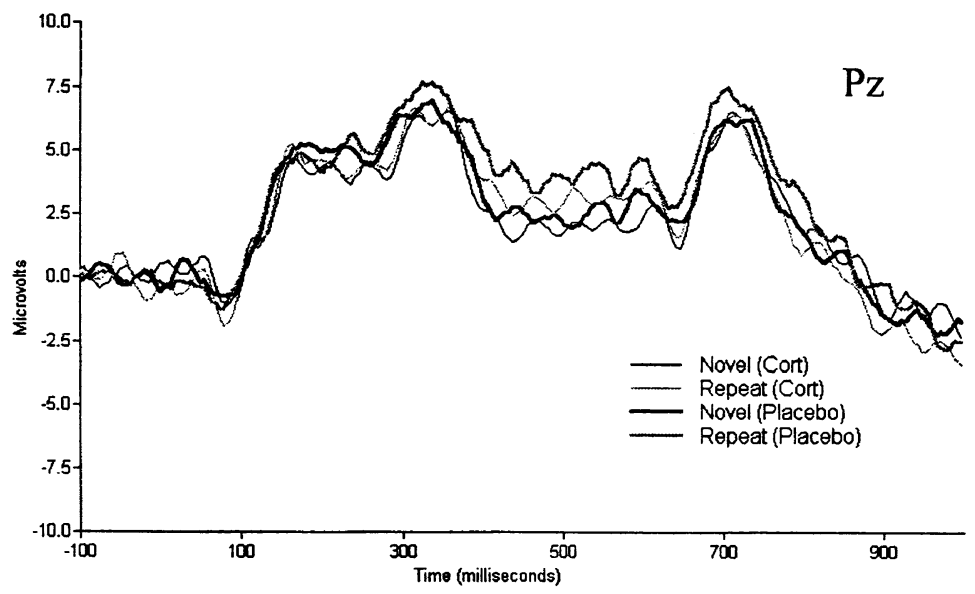

Attention. The ERP component of interest in the attention task was the P3b. This component was maximal over the parietal leads and the peak amplitude occurred at approximately $400 \mathrm{~ms}$. As with the behavioral data, analyses on the two phases of the attention task were conducted separately. In both Attention 1 and 2, there was no effect of drug and there was no drug and stimulus interaction, but there was an effect of stimulus for 

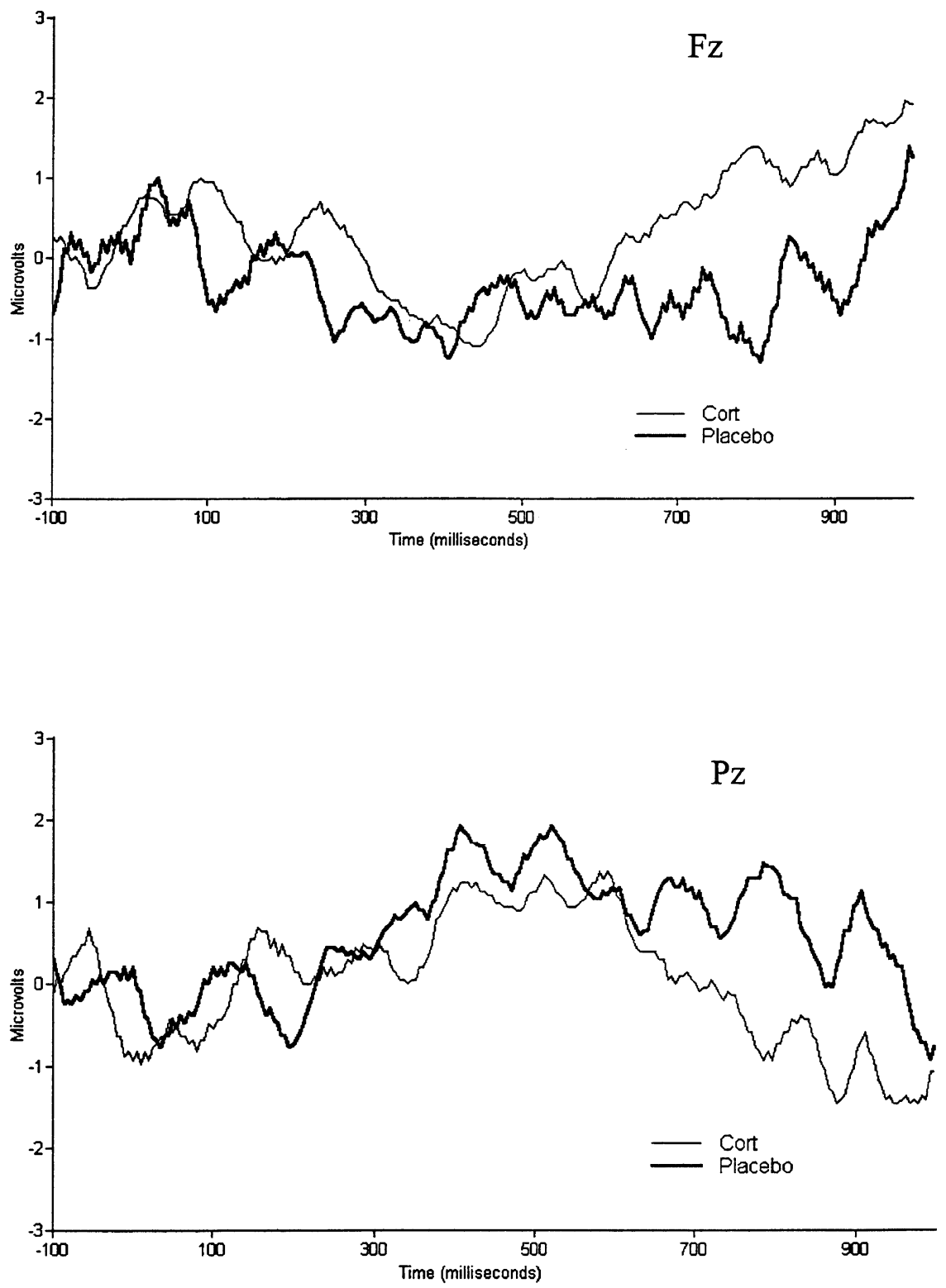

Figure 3. Difference waveforms for the short-term recognition memory task with faces. The upper graph depicts a difference waveform (novel-repeat) for $\mathrm{Fz}$, while the lower graph illustrates the difference waveform (repeat-novel) for Pz. The figure shows the increased activation to novel faces over the frontal lobe during hydrocortisone exposure (upper graph) and the reduced activation of to repeated faces during hydrocortisone exposure (lower graph) over the parietal lobe. the central, parietal and occipital leads, whereby the target stimulus elicited a greater $\mathrm{P} 3 \mathrm{~b}$ response.

Summary of the Electrophysiological Results. Hydrocortisone altered the ERP waveforms in the face recognition memory task following the short delay. In particular, there was a significant interaction of drug and stimulus, whereby hydrocortisone led to increased activation to novel stimuli in the frontal leads and a decreased response to repeat stimuli in more posterior leads. Furthermore, while significant effects in ERPs were found due to stimulus in recognition memory for objects, working memory and attention, hydrocortisone did not alter the ERP response in these tasks.

Pulse and Blood Pressure. The means and standard deviations for blood pressure and pulse are presented in Table 4 . There were no effects from the hydrocortisone on pulse, $\mathrm{F}_{1,23}=0.001, p=.977$, but the effect of time was significant, $\mathrm{F}_{2,46}=3.431, p<.05$. In contrast, an ANOVA revealed a significant effect of hydrocortisone on systolic blood pressure, $\mathrm{F}_{1,23}=4.796, p<.05$. However, in examining the means, it appears likely that this main effect of hydrocortisone was due to a difference that existed at baseline. Consequently, using an analysis of covariance, the effect of baseline was partialed out and there was no effect of hydrocortisone on systolic blood pressure, $\mathrm{F}_{1,21}=0.097, p=.759$. In addition, there was a significant effect of time for systolic blood pressure, $\mathrm{F}_{2,46}=15.908$, $p<.001$. For diastolic blood pressure, there was no effect of hydrocortisone, $\mathrm{F}_{1,23}=0.456, p=.506$, but time was once again significant, $\mathrm{F}_{2,46}=21.131, p<.001$.

PANAS. No significant differences were found from drug in subjects' responses to negative emotionality, 


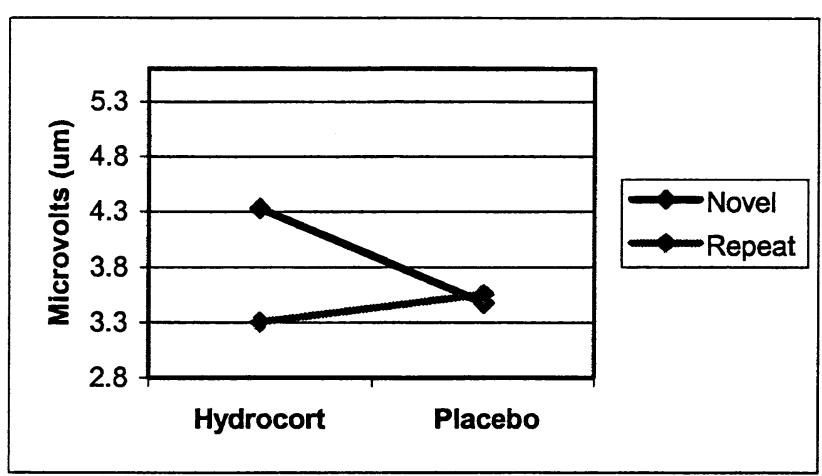

Frontal leads

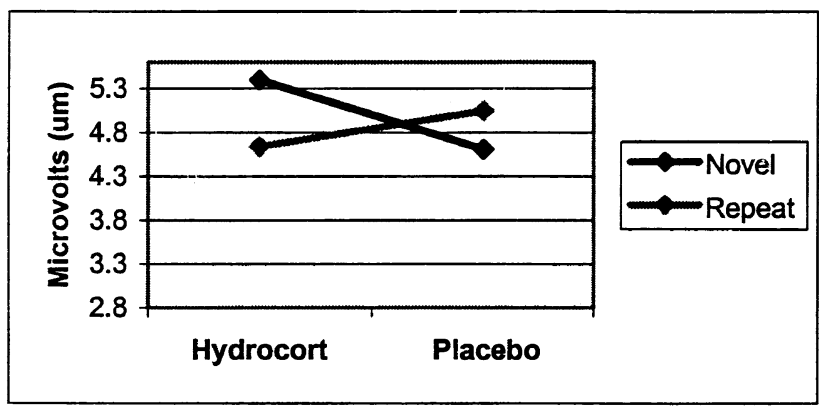

Central leads

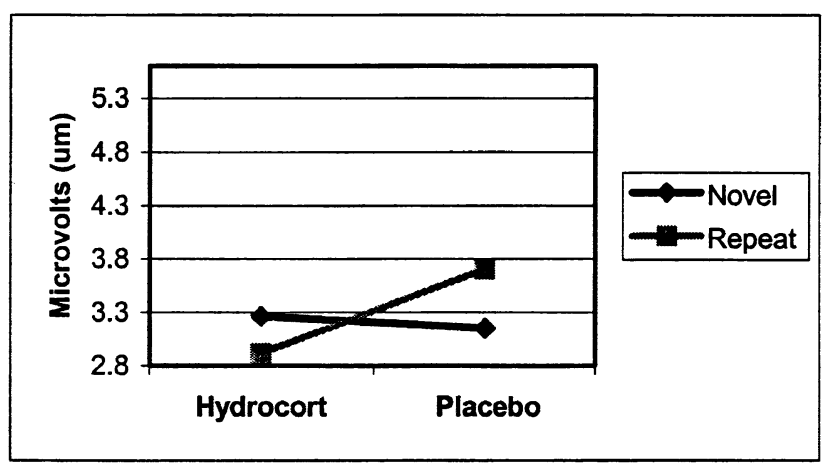

Parietal leads

Figure 4. Interactions for the P600 in the short-term test of face recognition. Points represent mean amplitude from all the leads in a given region.

$\mathrm{F}_{1,23}=0.150, p=.702$, or positive emotionality, $\mathrm{F}_{1,23}=$ $0.607, p=.444$.

\section{Examination of Relations between Physiological and Behavioral Measures}

Pearson $r$ correlations were conducted between the mean amplitude of the P600 over the parietal lobe (where the P600 is maximal) at the test of STM for repeat stimuli and behavioral accuracy on the LTM task for faces. The P600 at STM significantly correlated with
Table 4. Systolic and Diastolic Blood Pressure and Pulse

\begin{tabular}{|c|c|c|c|c|c|c|}
\hline & \multicolumn{2}{|c|}{ SYSTOLIC } & \multicolumn{2}{|c|}{ DIASTOLIC } & \multicolumn{2}{|c|}{ PULSE } \\
\hline & PLAC & CORT & PLAC & CORT & PLAC & CORT \\
\hline \multirow[t]{2}{*}{ BASELINE } & 114.625 & 112.042 & 64.383 & 63.625 & 64.750 & 64.542 \\
\hline & (11.956) & (10.540) & (6.093) & (6.093) & (7.421) & (10.471) \\
\hline \multirow[t]{2}{*}{ TIME 1} & 115.083 & 113.458 & 68.333 & 68.625 & 62.458 & 62.417 \\
\hline & (11.390) & (10.571) & (7.452) & $(6.540)$ & (8.772) & (7.901) \\
\hline \multirow[t]{2}{*}{ TIME 2} & 120.292 & 118.450 & 67.000 & 69.708 & 64.083 & 64.208 \\
\hline & (11.933) & (11.858) & (7.985) & (8.985) & (7.366) & (8.747) \\
\hline
\end{tabular}

the correct identification of repeat faces at the long delay in the drug and placebo conditions. Specifically, the correlation in the placebo condition was $r=0.534, p<$ .01 and the correlation in the hydrocortisone condition was $r=0.426, p<.05$.

\section{DISCUSSION}

The results from both the behavioral and ERP measures indicate that hydrocortisone altered the processing of explicit memory. Hydrocortisone led to impairments in face recognition following a 30-min delay. Also, with hydrocortisone, there were alterations in the P600 response in the face recognition task following a short delay (6-18 s). In particular, hydrocortisone was associated with greater activation to novel stimuli over the frontal lobe and reduced activation to repeated stimuli in more posterior regions of the scalp. However, contrary to the predictions, no alterations were found in the P600 after the long delay with faces, hydrocortisone was not associated with alterations in the N400 component, and the steroid did not alter behavioral performance or ERPs in explicit memory for objects. Meanwhile, hydrocortisone did not lead to any changes in the behavioral performance or ERPs in the other tasks (working memory and attention) and, finally, the drug exposure did not influence blood pressure, pulse or mood as measured by the PANAS.

In support of the validity of these ERP paradigms, significant differences were also found between stimuli. In the STM task for face and object recognition, the N400s showed a greater negativity for novel stimuli than repeat stimuli. In addition, LTM with objects, the P600 was greater for repeat stimuli. Meanwhile, target stimuli in working memory and attention elicited greater P3b components than nontarget stimuli. However, in contrast to expectations, there was no effect of stimulus type on the P600 for faces at STM or LTM, and the P600 at STM for objects was greater to novel than repeat stimuli.

Since explicit memory and the P600 are linked to the hippocampus (Düzel et al. 2001; Fernández et al. 1999; 
Grunwald et al. 1999), these results are consistent with previous investigations indicating that glucocorticoids affect hippocampal function. The pattern of the P600 component was particularly interesting. Hydrocortisone led to a decreased response to repeat stimuli over the parietal lobe, while the drug was associated with an increased response to novel stimuli over the frontal region (Figures 2-4). Since the P600 is typically manifested as an enhanced response to repeat relative to novel stimuli over the parietal area (e.g., Paller et al. 1999), the effect of hydrocortisone on novel stimuli over the frontal lobe was unanticipated. The neural activity underlying this ERP pattern may serve an adaptive function. During a stressful event, it may be more important for an organism to detect novelty than to recognize previously seen stimuli. Therefore, with high levels of cortisol circulating, the nervous system may differentially respond to novelty at the cost of reduced activity to repeat stimuli.

Another noteworthy finding to emerge from these data is that hydrocortisone altered the ERP response only at the test of short-term memory (6-18 s delay), but behavioral performance was not affected until the test of long-term memory. Perhaps the ERPs detected a neural dysfunction early in the encoding and consolidation phases that could not be behaviorally measured until the more challenging evaluation of memory was given: the long-term memory test. In support of the assertion that the P600 at the short-term memory test is related to behavioral recognition memory performance at the long delay, these two measures correlated in both the placebo and hydrocortisone conditions.

However, one recent study found that $25 \mathrm{mg}$ of cortisone only impaired recall memory for words when the drug was given prior to test of long-term memory and not when administered prior to or immediately following learning (de Quervain et al. 2000). In addition, no impairments were found in recognition memory. The authors conclude that cortisone may impair retrieval, but not encoding or consolidation. The present study was not designed to separate the effects of hydrocortisone on encoding and retrieval. It is possible that the behavioral effects found in the present study are due to impairments in retrieval at the 30-min delay. Nevertheless, since the present study documents memoryrelated ERP alterations during early memory processing, these results suggest that hydrocortisone may also affect mnemonic functioning before retrieval. de Quervain et al. (2000) used words and, therefore, it is possible that these discrepant results may be due differences in stimuli. Complex stimuli such as faces may recruit neural structures that are affected by cortisol prior to retrieval.

Meanwhile, hydrocortisone was predicted to decrease the response of the N400 to novel stimuli in the short-term memory tasks for faces and objects. While novel stimuli led to greater N400 responses in the face and object recognition tasks in the present study, hydrocortisone did not influence this component. Using indwelling electrodes, Guillem and colleagues found that the hippocampus was involved in the propagation of the N400 (Guillem et al. 1998). However, other studies reported that it was the parahippocampus and not the hippocampus proper that generated the N400 (Grunwald et al. 1998; Fernández et al. 1999). Moreover, in a recent study it was found that an individual with bilateral hippocampal and parahippocampal damage exhibited a normal N400 (Düzel et al. 2001). Thus, it is possible that hydrocortisone led to decreased hippocampal functioning without altering the N400. Conversely, it is also conceivable that the N400 emerges from fibers in the hippocampus that hydrocortisone does not affect.

While the findings that hydrocortisone impaired explicit memory and possibly the hippocampus are consistent with previous investigations, several studies with patients and monkeys revealed that chronically high levels of cortisol are associated with deficits in attention (Mauri et al. 1993; Lupien et al. 1994; Gurvits et al. 1996). What might account for these contradictory findings? Cortisol may exert different pathophysiological effects depending on the duration of exposure. In particular, cortisol may not affect attention along with their neural correlates immediately. Instead, in order for these processes to be affected, cortisol may alter the functioning of other neuromodulators over a long period of time and, in turn, these neuromodulators affect attention.

In a recent investigation, an acute exposure of hydrocortisone to healthy individuals led to impaired working memory, but no alterations in explicit memory (Lupien et al. 1999). The reason why deficits in explicit memory were not found may be because the measure lacked sensitivity. Only 12 word pairs (6 related and 6 unrelated pairs) were given for stimuli and subjects appear to have performed near ceiling for recall of the related items. In addition, the disparity in the effects on working memory in the present study and Lupien's work may be due to differences in the dose of hydrocortisone administered. In Lupien et al. (1999), participants received $0.040,0.300$ or $0.600 \mathrm{mg} / \mathrm{kg}$ per hour for $1 \mathrm{~h}$ and $40 \mathrm{~min}$. Therefore, an individual weighing $70 \mathrm{~kg}$ would receive a total of 4.67, 35 or $70 \mathrm{mg}$ of hydrocortisone, respectively. In addition, the study by Lupien and colleagues was conducted in the morning, a time of circadian cortisol peak. In contrast, all subjects in the present study received $30 \mathrm{mg}$ of hydrocortisone and it was conducted in the afternoon, a period when lower levels of cortisol are present. In the work by Lupien et al. (1999), only subjects who received the highest dose demonstrated working memory impairments. Thus, in order to adversely affect working memory, it may be necessary to administer high doses of hydrocortisone. 
The effects of glucocorticoids on memory have been more systematically examined in rodents and, therefore, these studies may more precisely reveal the mechanisms that underlie these alterations. Roozendaal and colleagues demonstrated that glucocorticoids' modulation of memory function in rats involves noradrenergic influence in the basolateral nucleus of the amygdala (BLA) as well as the stria terminalis (Roozendaal \& McGaugh, 1996; Roozendaal et al. 1999). The BLA-mediated effects of memory occur even when the hippocampus is the location of steroid infusion (Roozendaal et al. 1999). Furthermore, consistent with de Quervain and colleagues' human work described above (de Quervain et al. 2000), rats were impaired in retrieval memory for a water maze when corticosterone was administered 30 min before test (de Quervain et al. 1998). In humans, further work must be done to clarify which stages of memory and neural structures glucocorticoids modulate. Through the use of behavioral work that isolates the effects of the drug on memory stage, examination of patients with lesions to areas such as the amygdala and the use of functional imaging, the effects of cortisol on memory and neural functioning in humans may be more precisely identified.

\section{Limitations of the Present Investigation}

One shortcoming with these procedures is that the tasks were not always counterbalanced across duration of drug exposure. Specifically, while face and object stimuli were counterbalanced with one another and working memory and attention were also counterbalanced, a short-term memory task always preceded a working memory and attention task. In addition, a short-term memory task, by necessity, preceded a longterm memory task. Thus, while the salivary cortisol levels were elevated during and following the cognitive tasks, variations in cortisol levels within the brain may account for the differential effects on cognition and ERPs. Nevertheless, these results indicate that cortisol impairs explicit memory. By more systematically examining the effects of hydrocortisone on working memory and attention, future research may be able to more precisely determine whether this steroid affects these cognitive processes.

\section{Summary}

The behavioral and ERP results from the present study indicate that an acute exposure to hydrocortisone impairs explicit memory. Behaviorally, participants performed significantly worse in the test of long-term face recognition when exposed to hydrocortisone than with the placebo. The ERPs were only affected in the shortterm recognition memory task for faces. Moreover, both explicit memory and P600 are linked to hippocampal function. Finally, the present investigation did not reveal effects of hydrocortisone on working memory or attention as measured by behavioral performance and ERPs.

\section{ACKNOWLEDGMENTS}

This research is based on the doctoral dissertation of C.S.M. Financial support was provided by a Departmental Fellowship from the Institute of Child Development (C.S.M.), an Eva O. Miller Fellowship from the Graduate School (C.S.M.), an $\mathrm{NIH}$ grant to the Center for Cognitive Sciences (NIH Grant 5 T32 HD07151), NIH grant (NS 32976) awarded to C.A.N., a University of Minnesota Graduate School grant to the Center for the Study of Neurobehavioral Development in the Context of Adversity (Megan R. Gunnar), an award from the American Psychological Association (C.S.M.), a Dissertation Special Grant from the Graduate School (C.S.M.), and an NIH grant (MO-RR00400) to the Clinical Research Center, University of Minnesota. The authors acknowledge the valuable advice from Drs. Megan R. Gunnar, Patricia J. Bauer, Monica Luciana, Apostolos Georgopoulos and Bruce Overmier. In addition, Dr. Elizabeth Seaquist provided methodological advice, and Jeff Benson, Kim Pearson and Kelly Lauyons supplied technical assistance.

\section{REFERENCES}

Alvarez P, Zola-Morgan S, Squire LR (1995): Damage limited to the hippocampal region produces long-lasting memory impairment in monkeys. J Neurosci 15:3796-3807

Aronsson M, Fuxe K, Dong Y, Agnati LF, Okret S, Gustafsson JA (1988): Localization of glucocorticoid receptor mRNA in the male rat brain by in situ hybridization. Proc Natl Acad Sci USA 85:9331-9335

Cohen JD, Forman SD, Braver TS, Casey BJ, ServanSchreiber, Noll DC (1994): Activation of the prefrontal cortex in a nonspatial working memory task with functional MRI. Hum Brain Map 1:293-304

de Leon MJ, McRae T, Rusinek H, Convit A, de Santi S, Tarshish C, Golomb J, Volkow N, Daisley K, Orentreich N, McEwen B (1997): Cortisol reduces hippocampal glucose metabolism in normal elderly, but not in Alzheimer's disease. J Clin Endocrinol Metab 82:3251-3259

de Quervain DJ, Roozendaal B, McGaugh JL (1998): Stress and glucocorticoids impair retrieval of long-term spatial memory. Nature 394:787-790

de Quervain DJ, Roozendaal B, Nitsch RM, McGaugh JL, Hock C (2000): Acute cortisone administration impairs retrieval of long-term declarative memory in humans. Nat Neurosci 3:313-314

Diorio D, Viau V, Meaney MJ (1993): The role of the medial prefrontal cortex (cingulate gyrus) in the regulation of hypthalamic-pituitary-adrenal responses to stress. J Neurosci 13:3839-3847

Donchin E, Coles MGH (1988): Is the P300 component a manifestation of context updating? Behav Brain Sci 11:357-427

Düzel E, Vargha-Khadem F, Heinze HJ, Mishkin M (2001): Brain activity evidence for recognition without recollection after early hippocampal damage. Proc Natl Acad Sci USA 98:8101-8106 
Düzel E, Yonelinas AP, Mangun G, Heinze HJ, Tulving E (1997): Event-related brain potential correlates of two states of conscious awareness in memory. Proc Natl Acad Sci USA 94:5973-5978

Fernández G, Arndt E, Grunwald T, Pezer N, Lehnertz K, Dumpelmann M, Van Roost D, Elger CE (1999): Realtime tracking of memory formation in the human rhinal cortex and hippocampus. Science 285:1582-1585

Foy MR, Stanton ME, Levine S, Thompson RF (1987): Behavioral stress impairs long-term potentiation in rodent hippocampus. Behav Neural Biol 48:138-149

Grady CL, McIntosh AR, Horwitz B, Maisog JM, Ungerleider LG, Mentis MJ, Pietrini P, Schapiro MB, Haxby JV (1995): Age-related reductions in human recognition memory due to impaired encoding. Science 269:218-221

Grunwald T, Beck H, Lehnertz K, Blümcke I, Pezer N, Kutas M, Kurthen M, Karakas HM, Van Roost D, Wiestler OD, Elger CE (1999): Limbic P300s in temporal lobe epilepsy with and without Ammon's horn sclerosis. Eur J Neurosci 11:1899-1906

Grunwald T, Lehnertz K, Heinze HJ, Helmstaedter C, Elger CE (1998): Verbal novelty detection within the human hippocampus proper. Proc Natl Acad Sci USA 95:3193-3197

Guillem F, N'Kaoua B, Rougier A, Claverie B (1998): Location of the epileptic zone and its physiopathological effects on memory-related activity of the temporal lobe structures: A study with intracranial event-related potentials. Epilepsia 39:928-41

Gurvits TV, Shenton ME, Hokama H, Ohta H, Lasko NB, Gilbertson MW, Orr SP, Kikinis R, Jolesz FA, McCarley RW, Pitman RK (1996): Magnetic resonance imaging study of hippocampal volume in chronic, combatrelated posttraumatic stress disorder. Biol Psychiatry 40:1091-1099

Haxby JV, Ungerleider LG, Horwitz B, Maisog JM, Rapoport SI, Grady CL (1996): Face encoding and recognition in the human brain. Proc Natl Acad Sci USA 93:922-927

Jasper HH (1958): Report of the committee on methods of clinical examination in electroencephalography. Electroencephalogr Clin Neurophysiol 10:371-375

Kirschbaum C, Strasburger CJ, Jammers W, Hellhammer DH (1989): Cortisol and behavior: 1. Adaptation of a radioimmunoassay kit for reliable and inexpensive salivary cortisol determination. Pharmacol Biochem Behav 34:747-751

Kirschbaum C, Wolf OT, May M, Wippich W, Hellhammer DH (1996): Stress- and treatment-induced elevations of cortisol levels associated with impaired declarative memory in healthy adults. Life Sci 58:1475-1483

Knight RT, Scabini D, Woods DL, Clayworth CC (1998): Anatomic bases of event-related potentials and their relationship to novelty detection in humans. J Clin Neurophysiol 15:3-13

Lupien S, Lecours AR, Lussier I, Schwartz G, Nair NPV, Meaney M, J. (1994): Basal cortisol levels and cognitive deficits in human aging. J Neurosci 14:2893-2903

Lupien SJ, de Leon M, de Santi S, Convit A, Tarshish C, Nair NPV, Thakur M, McEwen BS, Hauger RL, Meaney MJ (1998): Cortisol levels during human aging predict hippocampal atrophy and memory deficits. Nat Neurosci 1:69-73
Lupien SJ, Gillin CJ, Hauger RL (1999): Working memory is more sensitive than declarative memory to the acute effects of corticosteroids: A dose-response study in humans. Behav Neurosci 113:420-430

Mauri M, Sinforiani E, Bono G, Vignati F, Berselli ME, Attanasio R, Nappi G (1993): Memory impairment in Cushing's disease. Acta Neurol Scand 87:52-55

McCarthy G, Wood CC (1987): Intracranial recordings of endogenous ERPs in humans. Electroencephalogr Clin Neurophysiol 39 (supplement):331-337

McEwen BS, Weiss JM, Schwartz LS (1968): Selective retention of corticosterone by limbic structures in rat brain. Nature 220:911-912

McEwen BS, Weiss JM, Schwartz LS (1969): Uptake of corticosterone by rat brain and its concentration by certain limbic structures. Brain Res 16:227-241

Meaney MJ (1985): [3H] Dexamethasone binding in the rat frontal cortex. Brain Res 328:176-180

Newcomer JS, Craft S, Hershey T, Askins K, Bardgett ME (1994): Glucocorticoid-induced impairments in declarative memory performance in adult humans. J Neurosci 14:2047-2053

Newcomer JW, Selke G, Melson AK, Hershey T, Craft S, Richards K, Alderson AL (1999): Decreased memory performance in healthy humans induced by stress-level cortisol treatment. Arch Gen Psychiatry 56:527-533

Nielsen-Bohlman L, Knight RT (1995): Prefrontal alterations during memory processing in aging. Cereb Cortex 5: 541-549

Paller KA, Bozic VS, Ranganath C, Grabowecky M, Yamada $S$ (1999): Brain waves following remembered faces index conscious recollection. Cognit Brain Res 7:519-531

Paller KA, Kutas M, Mayes AR (1987): Neural correlates of encoding in an incidental learning paradigm. Electroencephalogr Clin Neurophysiol 67:360-371

Paller KA, McCarthy G, Wood CC (1988): ERPs predictive of subsequent recall and recognition performance. Biol Psychol 26:269-276

Roozendaal B, McGaugh JL (1996): The memory-modulatory effects of glucocorticoids depend on an intact stria terminalis. Brain Res 709:243-250

Roozendaal B, Nguyen BT, Powers AE, McGaugh JL (1999): Basolateral amygdala noradrengergic influence enables enhancement of memory consolidation induced by hippocampal glucocorticoid receptor activation. Proc Natl Acad Sci USA 96:11642-11647

Ruchkin DS, Johnson R Jr, Canoune H, Ritter W (1990): Short-term memory storage and retention: An eventrelated potential study. Electroencephalogr Clin Neurophysiol 76:419-439

Sanchez MM, Young LJ, Plotsky PM, Insel TR (2000): Distribution of corticosteroid receptors in the rhesus brain: relative absence of glucocorticoid receptors in the hippocampal formation. J Neurosci 20:4657-4668

Sapolsky RM, Krey LC, McEwen BS (1985): Prolonged glucocorticoid exposure reduces hippocampal neuron number: implications for aging. J Neurosci 5:1222-1227

Sapolsky RM, Uno H, Rebert CS, Finch CE (1990): Hippocampal damage associated with prolonged glucocorticoid exposure in primates. J Neurosci 10:2897-2902 
Schacter DL (1994): Priming and multiple memory systems: perceptual mechanisms of implicit memory. in Schacter DL, Tulving E (eds), Memory Systems 1994. Cambridge, MA, The MIT Press, pp 233-268

Schacter DL, Reiman E, Uecker A, Polster MR, Yun LS, Cooper LA (1995): Brain regions associated with retrieval of structurally coherent visual information. Nature 376: 587-590

Schmidt LA, Fox NA, Goldberg MC, Smith CC, Schulkin J (1999): Effects of acute prednisone administration on memory, attention and emotion in healthy human adults. Psychoneuroendocrinology 24:461-483

Schnyer DM, Allen JJB, Forster KI (1997): Event-related brain potential examination of implicit memory processes: masked and unmasked repetition priming. Neuropsychology 11:243-260

Seckl JR, Dickson KL, Yates C, Fink G (1991): Distribution of glucocorticoid and mineralocorticoid receptor messenger RNA expression in human postmortem hippocampus. Brain Res 561:332-337

Shors TJ, Foy MR, Levine S, Thompson RF (1990): Unpredictable and uncontrollable stress impairs neuronal plasticity in the rat hippocampus. Brain Res Bull 24:663-667

Shors TJ, Thompson RF (1992): Acute stress impairs (or induces) synaptic long-term potentiation (LTP) but does not affect paired-pulse facilitation in the stratum radiatum of rat hippocampus. Synapse 11:262-265

Smith EE, Jonides J (1998): Neuroimaging analyses of human working memory. Proc Natl Acad Sci USA 95:12061-12068

Smith ME (1993): Neurophysiological manifestations of recollective experience during recognition memory judgements. J Cogn Neurosci 5:1-13

Sousa RJ, Tannery NH, Lafer EM (1989): In situ hybridization mapping of glucocorticoid receptor messenger ribonucleic acid in rat brain. Mol Endocrinol 3:481-494

Squires NK, Squires KC, Hillyard SA (1975): Two varieties of long-latency positive waves evoked by unpredictable auditory stimuli in man. Electroencephalogr Clin Neurophysiol 38:387-401

Starkman MN, Gebarski SS, Berent S, Schteingart DE (1992): Hippocampal formation volume, memory dysfunction, and cortisol levels in patients with Cushing's syndrome. Biol Psychiatry 32:756-765

Starkman MN, Giordani B, Gebarski SS, Berent S, Schork MA, Schteingart DE (1999): Decrease in cortisol reverses human hippocampal atrophy following treatment of Cushing's Disease. Biol Psychiatry 46:1595-1602

Stern CE, Corkin S, Gonzalez RG, Guimaraes AR, Baker JR, Jennings PJ, Carr CA, Sugiura RM, Vedantham V, Rosen BR (1996): The hippocampal formation participates in novel picture encoding: evidence from functional magnetic resonance imaging. Proc Natl Acad Sci USA 93:8660-8665

Swick D, Knight RT (1995): Contributions of right inferior temporal-occipital cortex to visual word and non-word priming. Neuroreport 7:11-16

Swick D, Knight RT (1997): Event-related potentials differentiate the effects of aging on word and nonword repetition in explicit and implicit memory tasks. J Exp Psychol Learn Mem Cogn 23:123-142

Watson D, Clark LA, Tellegen A (1988): Development and validation of brief measures of positive and negative affect: the PANAS scales. J Pers Soc Psychol 54:1063-1070

Watzka M, Beyenburg S, Blumcke I, Elger CE, Bidlingmaier F, Stoffel-Wagner B (2000a): Expression of mineralocorticoid and glucocorticoid receptor mRNA in the human hippocampus. Neurosci Lett 290:121-124

Watzka M, Bidlingmaier F, Beyenburg S, Henke RT, Clusmann H, Elger CE, Schramm J, Klingmuller D, StoffelWagner B (2000b): Corticosteroid receptor mRNA expression in the brains of patients with epilepsy. Steroids 65:895-901

Woolley CS, Gould E, McEwen BS (1990): Exposure to excess glucocorticoids alters dendritic morphology of adult hippocampal pyramidal neurons. Brain Res 531:225-231

Zola SM, Squire LR, Teng E, Stefanacci L, Buffalo EA, Clark RE (2000): Impaired recognition memory in monkeys after damage limited to the hippocampal region. J Neurosci 20:451-463

Zola-Morgan S, Squire LR, Amaral DG (1986): Human amnesia and the medial temporal region: enduring memory impairment following a bilateral lesion limited to field CA1 of the hippocampus. J Neurosci 6:2950-2967 